\title{
Magnesium Recycling: To the Grave and Beyond
}

\author{
CHAMINI L. MENDIS ${ }^{1,3}$ and ALOK SINGH ${ }^{2,4}$ \\ 1.-Helmholtz Zentrum Geesthacht, Magnesium Innovation Centre, 21502 Geesthacht, Germany. \\ 2.-National Institute for Materials Science, Ibaraki, Tsukuba 305-0047, Japan. 3.-e-mail: \\ chamini.mendis@hzg.de. 4.—e-mail: alok.singh@nims.go.jp
}

Demands for the reduction of carbon emissions imposed by the legislative bodies mean that magnesium and its alloys receive continued interest from the manufacturing industries. ${ }^{1}$ The use of alternative energy sources such as hybrid-, battery-, or fuel-cell-powered cars alleviates some of the environmental impact of using fossil fuels, but these technologies continue to require lighter materials to maintain fuel efficiency. Many of the lightweight materials such as fiber-reinforced polymers cannot be reused or recycled in the conventional ways. High-grade magnesium and magnesium alloy scrap can be easily recycled where the alloy composition can be controlled, such as defected parts in a die casting operation. However, where the alloys are mixed or the alloys contain impurity elements or oxide particles, the alloys cannot be easily recycled. ${ }^{2}$ As the use of the magnesium alloys increases the recycling of magnesium alloys becomes both environmentally and economically important. Moreover, various countries in the world regulate the end of life of the vehicles and the recycling of the parts. The European Union regulates the minimum amount for reuse and the recycling rates for automotive components. ${ }^{3}$ Canada, Japan, China, and some states in the United States also regulate the end of life of motor vehicles in order to recover, reuse, and recycle some of the materials.

The production of primary magnesium is an energy-intensive process with a large carbon footprint. This is especially the case with the conventional pigeon process or the electrolytic reduction of magnesium chloride. However, the use of secondary magnesium is much less energy intensive compared with the primary production. At present, the aluminum and magnesium components are separated from heavy metals such as steel. The recovered magnesium is used in secondary aluminum processing to

Chamini L. Mendis and Alok Singh are the guest editors for the Magnesium Committee of the TMS Light Metals Division and coordinators of the topic "Magnesium Recycling: To the Grave and Beyond" in this issue. regulate the concentration of magnesium. However, with the increased use of magnesium, a commercially viable method to separate magnesium and aluminum is essential. A new system to separate magnesium has been developed in Germany that distinguishes between magnesium and aluminum through their coefficients of friction. Thus, a commercially viable and environmentally sound recycling process can lead to increased use of magnesium alloys. Recently, many different methods of recycling have been investigated to determine their viability.

Several different technologies can be used to refine magnesium scrap, which can be broadly categorized as flux based and fluxless technologies. Flux refining technologies use a flux to protect the magnesium and another flux to clean the magnesium. An example of a refining process that uses fluxes to refine magnesium is described in the article titled "An Environmentally Friendly Process Involving Refining and Membrane Based Electrolysis for Magnesium Recovery from Partially Oxidized Scrap Alloy" by Xiaofei Guan, Uday B. Pal, and Adam C. Powell. They describe refinement of partially oxidized $\mathrm{Mg}-\mathrm{Al}$ alloy to recover magnesium using a flux containing $\mathrm{MgF}_{2}$ and $\mathrm{CaF}_{2}$.

The second mode for refining magnesium, the fluxless process, includes salt furnace technologies, gas filtering vacuum distillation, and hydrometallurgy. The methodology described by Fabrizio D'Errico, Gerardo Garces Plaza, Markus Hofer, and Shae K. Kim would be an example of a flux-free method. In their article titled "Final Assessment of Pre-industrial Solid-state Route for High Performance Mg-System Alloys Production: Toward Conclusion of the Green Metallurgy EU Project," use of magnesium chips in the production of new alloys containing $\mathrm{CaO}$ has been discussed alongside commercialization of such a process.

The third contribution is entitled "Life Cycle Assessment of Recycling of Magnesium Vehicle Components" by Simone Ehrenberger and Horst E. Friedrich. It looks at the life-cycle assessment of using magnesium alloys in automotive components. 
They calculate the environmental impact associated with the use of magnesium in the automotive products and the effect of recycling magnesium on reducing the carbon footprint. The carbon footprint can be drastically reduced with the use of secondary magnesium. The authors in this contribution suggest that secondary magnesium may be appropriate for noncritical parts where the full optimization of property profiles is not essential.

The fourth contribution is from I.-H. Jung, S. Cui, J.-K. Lee and S. Park is entitled "Thermodynamics of the Mg Recycling Process". In this contribution the thermodynamics associated with the chemical reactions between molten $\mathrm{Mg}$ and the fluxes used is considered. The liquidus temperature and density of the flux play an important role as the attachment of $\mathrm{MgO}$ to flux is essentially physical and not chemical.

\section{REFERENCES}

1. Magnesium Vision 2020: A North American Automotive Strategic Vision for Magnesium (Southfield, MI: USCAR, 2006), http://www.uscar.org/commands/files_download.php? files_id $=240$.

2. A. Javaid, E. Essadiqi, S. Bell, and B. Davis, Magnesium Technology, ed. A.A. Luo N.R. Neelameggham, and R.S. Beals (Warrendale, PA: TMS, 2006), pp. 7-12.

3. Directive 2000/53/EC of the European Parliament and of the Council of 18 September 2000 on End-of-Life Vehicles: Commission Statements (Brussels, Belgium: European Commission, 2000), http://eur-lex.europa.eu/LexUriServ/LexUriServ. do?uri=CONSLEG:2000L0053:20050701:EN:PDF 